\title{
INTERVENÇÃO COM FAMÍLIAS CUJOS FILHOS SÃO SURDOCEGOS
}

\author{
INTERVENTION WITH FAMILIES WHO'S CHILDREN ARE DEAFBLIND
}

\author{
Fatima Ali Abdalah Abdel CADER-NASCIMENTO ${ }^{1}$ \\ Maria Piedade Resende da COSTA ${ }^{2}$
}

RESUMO: A família é o agente mediador primário entre o indivíduo e as demais unidades da sociedade. Sofre interferência nos casos da presença de uma alteração no desenvolvimento do filho. O presente estudo teve como objetivo implementar e avaliar um programa de intervenção que fornecesse oportunidades crescentes de desenvolvimento de novas competências nos pais, em relação às possibilidades e as técnicas de comunicação mais viáveis com suas filhas surdocegas. Participaram duas famílias que possuem filhas surdocegas (identificadas como 9F e 7F), pré-lingüísticas, ambas com surdez profunda bilateral associadas à baixa visão monocular. A coleta de dados ocorreu 106 encontros com as famílias, distribuídos em formas de atividades distintas: avaliação inicial, reuniões, aulas abertas, troca de informações, visitas às residências e avaliação final. $O$ aspecto mais destacado pelas famílias foram o desenvolvimento e ampliação dos recursos de comunicação. Este fato promoveu mudanças positivas e importantes no comportamento das filhas. Provavelmente, o progresso e as conquistas obtidas pelos participantes só se tornaram viáveis em função dos contatos constantes estabelecidos entre a escola e o contex to familiar.

PALAVRAS-CHAVE: Educação especial. Surdocegueira. Comunicação. Mediação.

ABSTRACT: The family is the primary agent mediator between the individual and the other units of the company. Interfered in cases of the presence of a change in the child's development. The present study aimed to implement and evaluate an intervention program that provides increasing opportunities for developing new skills in parents, about the possibilities and techniques of communication more viable with their deafblind children. Two families that have daughters deafblind (labeled $7 F$ and 9F), pre - linguistic, both with bilateral profound hearing loss associated with low vision monocular participated. Data collection occurred 106 meetings with families, distributed forms of distinct activities: initial assessment, meetings, open classes, information exchange, home visits, and final evaluation. The most prominent aspect of the families were the development and expansion of communication resources. This fact has promoted positive and important changes in the behavior of daughters. Probably the progress and achievements made by the participants only became feasible due to the constant contacts established between school and family context.

\section{KEYWORDS: Special Education. Deaf-Blind. Communication. Mediation.}

${ }^{1}$ Centro Universitário de Distrito Federal (UDF), Brasília - DF - Brasil. E-mail: pabdalah@ @ol.com.br.

${ }^{2}$ Universidade Federal de São Carlos (UFSCar), São Carlos - SP - Brasil. E-mail: piedade@ ufscar.br. 


\section{Introdução}

A família é o agente mediador primário entre o indivíduo e as demais unidades da sociedade. Esta mediação primária sofre interferência na presença de depressão materna, paterna, do bebê ou nos casos da presença de uma alteração no desenvolvimento. Nestes casos as reações desencadeadas são ao mesmo tempo singulares e universais em cada família. Telford e Sawrey (1988) apontam que a forma como a família enfrenta a "decepção e o trauma inesperado (ou esperado) é uma experiência universal". Na mesma perspectiva, Regen, Ardore e Hoffmann (1993) destacam que o momento e a forma pela qual os pais entram em contato com o problema de um filho deficiente são determinantes do processo posterior de aceitação da condição de ter alguma alteração orgânica.

Ao discutirem os problemas suscitados pela presença de um deficiente na família Telford e Sawrey (1988) identificaram oito etapas vivenciadas no contexto imediato: 1/autocomiseração; 2/ansiedade; 3/ambivalência; 4/culpa; 5/projeção; 6/vergonha; 7/depressão; 8/autopunição. Estas etapas estão diretamente vinculadas ao processo em si, as suas especificidades, porém a forma como a família recebe a notícia pode interferir e influenciar as ações futuras. A este respeito Chacon (1999) ao estudar a descoberta da deficiência por um grupo de mães de deficientes mentais evidenciou que todos os profissionais apresentaram para as mães os aspectos negativos da deficiência em si sem evidenciarem perspectivas positivas. Cader-Nascimento e Costa (2007) apontam que a surdocegueira congênita, pré-lingüística, reduz as possibilidades de aprendizagem incidental da criança. Porém, enfatizam que a partir do momento em que família e a criança começam a ter acesso aos recursos de comunicação alternativa e ao atendimento especializado novas perspectivas de aprendizagem e desenvolvimento se fortalecem e redimensionam a interação do grupo familiar.

Diante destes dados elaborou-se este estudo com vistas a implementar e avaliar um programa de intervenção que fornecesse oportunidades crescentes de desenvolvimento de novas competências nos pais, em relação às possibilidades e as técnicas de comunicação mais viáveis com suas filhas surdocegas.

\section{Método}

O estudo se pautou em três momentos distintos e complementares: avaliação inicial, intervenção e avaliação final. A inicial consistiu na realização de entrevistas com os pais na 
escola e nas residências. A intervenção pautou-se em cinco formas de atuação: aulas abertas para alunos com surdocegueira com participação dos pais, visitas às residências, reuniões programadas no calendário escolar, contatos por telefone e intervisitação. Na avaliação final realizou-se uma entrevista semi-estruturada. As atividades foram desenvolvidas em locais habituais: a escola e as residências. Ocasionalmente utilizaram-se espaços públicos para a realização de atividades extra-classe. Ao todo foram realizados 106 encontros, distribuídos nas cinco modalidades de atuação.

Participaram duas famílias que possuem filhas surdocegas, pré-lingüísticas, ambas com surdez profunda bilateral associadas à baixa visão monocular, com prognóstico de perda progressiva da eficiência visual, matriculadas numa escola especial, pública, do Distrito Federal. As famílias foram identificadas pela convenção $9 \mathrm{~F}$ e $7 \mathrm{~F}$, os números significam a idade das crianças, na época da pesquisa, a letra representa a palavra família. O Quadro 1 mostra o perfil de cada família.

Quadro 1: Perfil das famílias participantes

\begin{tabular}{|c|c|c|c|c|}
\hline \multirow[t]{2}{*}{ Critérios } & \multicolumn{2}{|c|}{ família 9F } & \multicolumn{2}{|c|}{ família $7 \mathrm{~F}$} \\
\hline & pai & Mãe & pai & mãe \\
\hline Idade em anos (no início da pesquisa) & 40 & 38 & 30 & 31 \\
\hline Idade em anos dos filhos & \multicolumn{2}{|c|}{9,15 e 17} & \multicolumn{2}{|c|}{$9,7,4,2$ e 1 mês } \\
\hline Escolarização dos pais & 6 série & $8^{a}$ série & $5^{\text {a }}$ série & $8^{a}$ série \\
\hline Ocupação profissional & garçom & do lar & vendedor & do lar \\
\hline Renda em salários mínimos & $3 \mathrm{sm}^{*}$ & 0 & $4 \mathrm{sm}$ & 0 \\
\hline Habitação & \multicolumn{2}{|c|}{ Aluguel } & \multicolumn{2}{|c|}{ casa cedida } \\
\hline Distância casa - escola em km & \multicolumn{2}{|c|}{40} & \multicolumn{2}{|c|}{30} \\
\hline Quem mais brinca com a criança & & $\mathrm{X}$ & & irmã \\
\hline De quem a criança parece gostar mais & $\mathrm{X}$ & & $\mathrm{X}$ & \\
\hline Quem fica mais tempo com a criança & & $\mathrm{X}$ & & $\mathrm{X}$ \\
\hline
\end{tabular}

Fonte: Elaboração própria. Entrevista com os pais (ambos progenitores), ${ }^{*}$ sm usado para salário mínimo.

O baixo nível de escolarização provavelmente reduziu as oportunidades de opção de trabalho, consequentemente, interferiu no rendimento de ambas as famílias. Somente a filha 9F participa do programa de aposentadoria do governo federal. Apesar da Constituição da República Federativa do Brasil (BRASIL, 1988) assegurar liberdade, o direito e a disposição da educação pública a todos os cidadãos, não há uma relação de equivalência entre a 
uniformidade de oportunidades com a igualdade das mesmas.

\section{Avaliação inicial}

Esta fase compreendeu o desenvolvimento de duas etapas: contato inicial e entrevista com base em formulário. No contato inicial esclarecemos sobre a pesquisa, as metas programadas e os compromissos éticos com a família e escola, na sequiência houve a assinatura do termo livre e esclarecido de consentimento em participar do estudo. Na entrevista ouvimos os pais, encorajando-os a discorrer sobre a interação com suas filhas, bem como a percepção deles sobre o desenvolvimento e as potencialidades das mesmas. Buscou conhecer as singularidades de cada família em relação à identificação pessoal, condição econômica, social e cultural, caracterização da relação afetiva vivenciada com a filha surdocega (SC), às experiências na época da descoberta da deficiência, principais redes de apoio, modalidade de comunicação estabelecida e, principalmente, as expectativas em relação à participação na pesquisa.

\section{Intervenção}

Desenvolvemos atividades com a família de acordo com as seguintes formas de atuação: a) reuniões convencionais; b) aulas abertas; c) contato por telefone; d) visita domiciliar; e) intervisitação dos pais, isto é, visita as residências. Para cada uma elaboraramse materiais, objetivos e procedimentos específicos. Os objetivos comuns foram: 1) envolver os pais com a escolarização de suas filhas, fortalecendo a crença da capacidade deles na interação e no processo de desenvolvimento delas; 2) possibilitar informações sobre a natureza da deficiência e alternativas de comunicação entre pais, filhas e escola; 3) motivar e incrementar as freqüências das respostas das filhas ao ambiente; e, 4) possibilitar uma adaptação mútua das condutas (pais / filhas).

\section{Reuniões}

As reuniões estavam previstas no calendário oficial da escola e foram realizadas com ênfase no progresso das crianças. Planejou-se a exibição de dois filmes clássicos: "O milagre de Anne Sullivan" e "Os transformadores". Os pais eram orientados sobre os setores de atendimento público no que se refere a locais de: a) aquisição de Aparelho de Amplificação Sonora Individual - AASI; b) realização de exames audiológicos e visuais; c) treino de fala; d) 
serviço de orientação para o trabalho; e) leitura e explicação dos laudos médicos; f) participação em associação de pais; g) distribuição gratuita de colírio de alto custo.

\section{Aulas abertas}

As aulas abertas consistiam na participação dos pais nas atividades próprias da sala de aula com suas filhas. Visou dar oportunidade à família de compartilhar as situações e os êxitos das filhas. O procedimento adotado consistiu em:

a) convidar os acompanhantes (pai, mãe, prima) para participar das atividades;

b) explicar, estimular e valorizar a participação do acompanhante;

c) demonstrar a dinâmica da atividade para os pais através de exemplos concretos;

d) orientar a sequiência da participação de cada um. Geralmente, os pais eram os últimos, possibilitando um tempo maior de observação;

e) quantificar e comparar o resultado de cada participante;

f) comemorar a vitória com muito entusiasmo por meio de aplausos, beijos, abraços, aperto de mão, fala, entre outros gestos naturais. No caso do último lugar as reações consistiram no gesto do dedo polegar para baixo, simulação de choro, etc;

g) entregar material semelhante ao da atividade desenvolvida em sala, para que pudessem brincar em outros ambientes.

\section{Contatos por telefone}

Visando acompanhar as manifestações das crianças em suas casas, a pesquisadora telefonava para os pais uma vez por semana, caso não tivesse a informação na escola.

\section{Visita domiciliar}

Foram previstas visitas às residências com um intervalo de dois meses, com vistas a: a) observar a interação; b) envolver o núcleo familiar no processo de aprendizagem e desenvolvimento das filhas $\mathrm{SC}$; c) esclarecer dúvidas; e) orientar e ensinar sistemas alternativos de comunicação. Atividades lúdicas (jogos) foram programadas para que todos participassem. Outro procedimento foi a identificação dos membros da família através de fichas, escritas com fita adesiva de cores variadas e a orientação sobre o calendário adaptado.

\section{Intervisitação das famílias}

A intervisitação viabilizada pela pesquisadora, em seu próprio veículo, teve por 
objetivo aumentar a proximidade das famílias, possibilitando trocas de informações a respeito de suas experiências de vida fortalecendo a cumplicidade entre elas.

\section{Avaliação final}

Realizou-se uma entrevista semi-estruturada em relação ao grau de satisfação dos pais com o trabalho. As informações foram organizadas segundo: a) data; b) forma (telefone ou pessoalmente); c) quem informou; d) enunciado. Os dados foram quantificados em relação a frequência e analisados qualitativamente por meio de categorias organizadas a partir dos relatos dos pais.

\section{Resultados e discussão}

Estavam previstos 106 encontros, distribuídos em cinco formas de atividades distintas. O Quadro 2 apresenta uma síntese destas atividades previstas em relação às realizadas.

Quadro 2: Participação das famílias

\begin{tabular}{|l|c|c|c|}
\hline Atividades & Previstas & \multicolumn{2}{|c|}{ Realizadas } \\
\cline { 3 - 4 } & & Família 9F & Família 7F \\
\hline Reuniões & 05 & 5 & 4 \\
\hline Aulas abertas & 55 & 48 & 15 \\
\hline Troca de informações & 41 & 74 & 47 \\
\hline Visitas às residências & 05 & 3 & 5 \\
\hline Total & 106 & 130 & 71 \\
\hline
\end{tabular}

Fonte: Elaboração própria. Anotações no caderno de campo e formulário de registro dos relatos das famílias.

Conforme as informações indicadas no Quadro 2, a família 9F participou de 100\% (5) e a 7F de $80 \%$ (4) das reuniões realizadas. Ressalta-se que o comparecimento da família 7F mobilizava o pai, a mãe, o bebê recém-nascido, 7F e uma irmã; enquanto na 9F houve alternância entre o pai (1) e a mãe (4). Nota-se que apesar das dificuldades as famílias se organizaram para estarem presente. Talvez esta mobilização esteja relacionada ao fato dos aspectos positivos do comportamento das filhas serem sempre enfatizados durante as reuniões. Quanto aos filmes, os dados evidenciaram que a exibição do filme "O milagre de 
Anne Sullivan" não atingiu os objetivos esperados. Houve dispersão, movimentação no banco, conversa paralela e comentários, como:

\section{[...] tá vendo, a surdocega tem uma professora só para ela [...](mãe 9F) \\ [...] a professora mora na casa dela [...] (mãe $7 F)$.}

Este comportamento associado à dificuldade de conciliar a disponibilidade de tempo e a necessidade dos pais em dividir sua atenção entre o filme e os filhos menores, acarretou a decisão de alterar a programação, substituindo os filmes pela exibição das gravações do desempenho das filhas na escola. Os pais demonstraram interesse, permaneciam atentos, realizavam comentários como:

\section{[...] como a professora têm paciência para explicar as coisas... eu preciso ter mais paciência para ensinar (pai $9 F$ ) \\ [...] é a segunda mãe da $7 F$,é por isso que eu não tenho coragem de tirar minha filha daqui... nossa minha filha consegue fazer isto... eu nunca vi minha filha fazendo isto [...] (mãe $7 F$ )}

Os comentários dos pais, para Telford e Sawrey (1988) são decorrentes da necessidade que eles têm de verem que seus filhos com necessidades especiais sejam aceitos de maneira calorosa e plena no ambiente escolar e que possam dar respostas coerentes às situações propostas. Geralmente, ao final das sessões as famílias solicitavam o material (fitas de vídeo ou DVD e fotografias) para levar e mostrar para os avós e tios que moravam em outra cidade. Este dado reforça a importância do núcleo familiar acompanhar o trabalho desenvolvido pela escola. Provavelmente, este fato motivou-os a colaborarem espontaneamente com o processo educacional dos mesmos, como mostra a seguinte fala:

[...] se a professora que não é da família está se dedicando tanto para ela aprender as coisas; nós que somos da família temos que ajudar [...] (pai $9 F$, ago)

Das 55 aulas abertas 23 envolveram uma programação extraclasse e 32 foram realizadas no espaço escolar. A família $9 \mathrm{~F}$ teve uma participação de $88 \%$, sendo que em $22 \%$ houve a participação de mais de um membro. Já a $7 \mathrm{~F}$ participou de $27 \%$ dos encontros no primeiro semestre. No caso da 7F a família encontrou dificuldades para administrar sua participação devido aos outros filhos. 
Estava previsto que a pesquisadora iria entrar em contato por telefone com os pais uma vez por semana, no entanto os pais, espontaneamente, começaram a ter esta iniciativa, por meio de ligações, bilhetes e conversa informal na escola, conforme mostra a Fig. 1.

Figura 1: Frequência dos comentários realizados pelas famílias

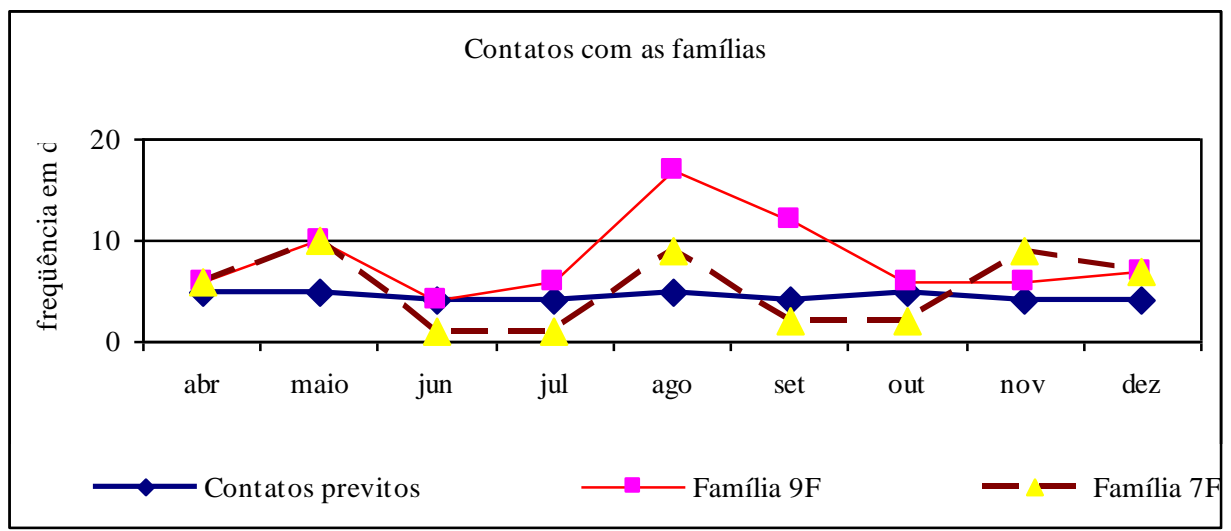

Fonte: Dados da pesquisa. Anotações no caderno

Nota-se, na Figura 1 que a família 9F é mais frequente em termos de informações espontâneas e adicionais do que a 7F. Este comportamento pode ser decorrente de vários fatores, entre eles: a) presença constante de um membro 9F na escola; b) 7F com um maior número de filhos (Quadro 1); c) dificuldades da 7F em se dirigir ao telefone público com três filhos pequenos, sendo um recém-nascido; d) expectativas das famílias frente às possibilidades e ao potencial de desenvolvimento das filhas surdocegas. Aliado a estes fatores é importante destacar algumas alterações nas relações sociais do núcleo familiar 7F, marcadas pelo nascimento, no mês de maio, de um menino. A chegada de mais um filho e, neste caso, do sexo masculino, tão esperado e desejado pelos pais que o denominaram de "herdeiro, aquele que irá pôr ordem na casa $[. .$.$] ", alterou o comportamento da família, conforme mostra$ a fala da filha mais velha:

[...] não está nada bem. O papai fica falando que a gente vai ter que obedecer o E (irmão) só por que ele é homem. Eu não vou obedecer ninguém. (irmã $7 F$, maio).

A Figura 2 mostra a frequência de informação espontânea em relação ao informante. 
Figura 2: Frequência de informação das famílias

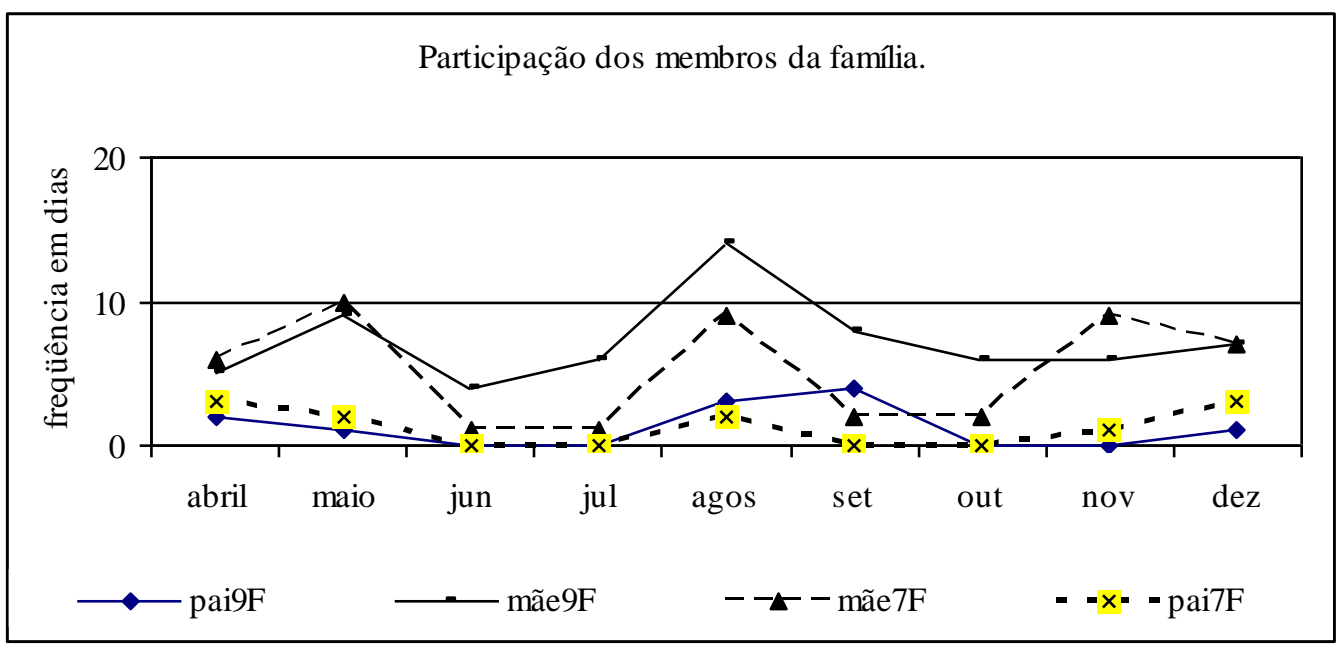

Fonte: Dados da pesquisa. Caderno de campo.

Os dados mostram a frequência maior das mães como informantes dos processos de desenvolvimento de seus filhos. Estes resultados são compatíveis com o estudo de Murdoch (1994) no qual constatou a baixa frequência do pai no processo de desenvolvimento do filho com surdocegueira. Segundo Telford e Sawrey (1988) a mãe, em geral, assume a responsabilidade central no cuidado e supervisionamento do desenvolvimento de sua prole, independente do fato destes serem ou não deficientes. Em relação à participação dos pais, os comentários foram poucos e, em geral, ocorreram nas reuniões escolares ou nas visitas às residências. Os dados mostraram que as famílias parecem designar a mãe como participante mais ativa no processo de escolarização dos filhos enquanto cabe ao pai garantir a manutenção econômica do grupo.

Ressalta-se que durante as conversas ao telefone com o núcleo $9 \mathrm{~F}$ eles sempre colocavam a filha para falar com a pesquisadora. Esta iniciativa, por um lado evidencia o desejo deles em ver a filha falando; por outro lado, mostra como eles buscam inserir a filha surdocega no contexto familiar. Neste contexto, surdez profunda da filha a impedia de ter acesso à informação, porém ao colocar o fone no ouvido ela demonstrava satisfação de emitir sons distintos, contando sua história. $\mathrm{O}$ acesso às informações era garantido na medida em que os pais realizavam a tradução dos sinais e gestos realizados pela filha durante a interação com a pesquisadora. Dessa forma, era possível saber o que ela estava transmitindo, sendo possível, posteriormente, comentar o assunto em sua presença. A partir de dezembro, quando a filha aprendeu a utilizar o telefone começou a realizar ligações de forma independente, muitas das quais os pais só ficavam sabendo quando as pessoas comentavam o fato com eles. 
Os enunciados espontâneos dos pais foram organizados em quatro aspectos básicos para análise de conteúdo. Os resultados obtidos são apresentados no Quadro 2.

Quadro 2: Síntese dos resultados obtidos na avaliação inicial e final com a família

\begin{tabular}{|l|l|l|l|l|}
\hline \multirow{2}{*}{$\begin{array}{l}\text { Aspectos } \\
\text { observados }\end{array}$} & \multicolumn{4}{|c|}{ Participantes } \\
\cline { 2 - 5 } $\begin{array}{l}\text { Av. inicial 9F } \\
\text { comunicação } \\
\text { apresentados }\end{array}$ & $\begin{array}{l}\text { Av. final 9F } \\
\text { gestos, } \\
\text { nervosismo). }\end{array}$ & $\begin{array}{l}\text { Av. inicial 7F } \\
\text { (fala, gestos, } \\
\text { Libras, Braille...). }\end{array}$ & $\begin{array}{l}\text { Avingar final 7F } \\
\text { nervosismo). }\end{array}$ & $\begin{array}{l}\text { (extinção das } \\
\text { birras e gritos). }\end{array}$ \\
\hline $\begin{array}{l}\text { Interação com } \\
\text { a filha }\end{array}$ & $\begin{array}{l}\text { Dificuldades de } \\
\text { entender a filha }\end{array}$ & $\begin{array}{l}\text { Facilidade em } \\
\text { entender a filha. }\end{array}$ & $\begin{array}{l}\text { Dificuldade em } \\
\text { controlar a filha. }\end{array}$ & $\begin{array}{l}\text { Facilidade em } \\
\text { entender a filha. }\end{array}$ \\
\hline $\begin{array}{l}\text { Adaptação do } \\
\text { ambiente }\end{array}$ & Ambiente & Adequação do & $\begin{array}{l}\text { Ambiente } \\
\text { inadequado. }\end{array}$ & $\begin{array}{l}\text { Alterações no } \\
\text { ambiente. }\end{array}$ \\
\hline $\begin{array}{l}\text { Expectativas } \\
\text { da pesquisa }\end{array}$ & Baixa & alta & baixa & alta \\
\hline
\end{tabular}

Fontes: Elaboração própria. Anotações no caderno de campo e entrevistas com base em formulário.

Em relação aos recursos de comunicação expressiva e receptiva houve um progresso no desenvolvimento dos mesmos em ambos os casos. A ampliação destes recursos promoveu melhores condições de acesso às informações pelas crianças surdocegas e suas famílias. Assim, durante a avaliação inicial, a família 9F relatava como:

É difícil entendê-la e explicar as coisas para ela. Ela é muito nervosa. Eu falo normal com ela", na avaliação final comenta que: "Agora é mais fácil entendê-la. Ela fala, mostra o que quer, desenha, tá mais calma.

O mesmo processo ocorreu com a família da 7F. Segundo seus pais, era difícil controlar seus comportamentos:

Eu não dou conta de controlá-la; não sei como ensinar para ela. Ela é muito nervosa", já na avaliação final os pais declaram que "[...] agora, ela tá mais calma. É mais fácil entendê-la e ela entende o que eu quero.

Durante a avaliação final os pais sinalizaram uma compreensão mais ampla do desenvolvimento de suas respectivas filhas, atribuindo a si mesmo incompetência em entendêlas e em se fazerem entendidos por elas. Com isto o desenvolvimento passa a ser visto como fruto das condições socioculturais vivenciadas e não como decorrente exclusivamente da 
gama de incompetências atribuídas à pessoa com alguma deficiência.

Com relação à adaptação do ambiente às condições visuais das filhas, apenas a família $7 \mathrm{~F}$, provavelmente, por não ter tido acesso às informações sobre a iluminação e disposição dos móveis no espaço, não havia até o início da intervenção realizado qualquer adaptação. Assim, no caso desta família, quando a pesquisadora realizou a segunda visita, a mãe comentou sobre a troca de todas as lâmpadas da casa de baixa para alta potência, conforme fala da mãe:

Você viu Fatima; nós trocamos todas as luzes daqui de casa. Agora a casa está mais clara. Ficou melhor para todo mundo, você viu?.

Aliado a esta mudança, o núcleo 7F reorganizou a disposição dos móveis da casa e acatou as sugestões para adaptações no uso e no armazenamento de utensílios, equipamentos e produtos de limpeza.

No caso da família 9F houve apenas a sugestão da troca do fósforo pelo acendedor de fogão, uma vez que a própria filha realizava o controle de iluminação na parte interna da casa, conforme relata a mãe:

Ela sempre deixa as janelas abertas. Ela gosta de ficar na varanda, acho que é porque é mais claro. Eu não deixo nada no meio da sala, para evitar que ela tropece. Os cabos das panelas estão sempre para dentro do fogão. Ela não gosta de escuro.

Conforme já mencionado, inicialmente, a expectativa das famílias em relação às possibilidades de aprendizagem e desenvolvimento de suas filhas era baixa, conforme mostra os seguintes depoimentos: "Espero que seja melhor para ela" (9F); e, "Que ela pare de dar birra" $(7 F)$. Notava-se que os pais não se sentiam muito à vontade para discorrer sobre seus projetos e desejos relacionados as filhas surdacegas. Um fato que ilustra esta postura refere-se ao sonho dos pais da filha 9F de vê-la falar. Algo que, antes da pesquisa parecia impossível, durante a pesquisa tornou-se mais acessível. Ao final da pesquisa os pais são unânimes em relatar que: "Foi bom demais para todos nós"(9F); e, "Minha filha agora é outra"(7F).

\section{Considerações finais}

$\mathrm{O}$ aspecto mais destacado pelas famílias foi o desenvolvimento e ampliação dos recursos de comunicação. Este fato promoveu mudanças positivas e importantes no 
comportamento das filhas. Provavelmente, o progresso e as conquistas obtidas pelos participantes e relatadas, espontaneamente, pelas famílias, só se tornaram viáveis em função dos contatos constantes estabelecidos entre a escola e o contexto familiar. Esta interação escola/família tornou os pais os principais colaboradores no processo de aprendizagem e desenvolvimento delas.

Enfim, os dados obtidos confirmaram os resultados da pesquisa desenvolvida por Watkins et al. (1991) e evidenciaram a importância de se manter atividades nas residências e contar com a participação de membros da família no espaço escolar. Com isto amplia-se a cumplicidade entre professores e família. Além disto, os resultados obtidos neste estudo superaram as dificuldades encontradas no estudo de Mira e Hoffaman (1974) em relação ao envolvimento da família no processo educacional de seus filhos. Enfim, parece que com a realização dessa pesquisa foi possível reduzir o estresse parental e contribuir para maior compreensão dos pais em relação às possibilidades de aprendizagem e desenvolvimento de suas filhas surdocegas.

\section{REFERÊNCIAS}

BRASIL. Secretaria de Educação. Constituição: República Federativa do Brasil. Brasília, 1988.

CADER-NASCIMENTO, F. A. A. A.; COSTA, M. P. R. da. Descobrindo a surdocegueira: Educação e Comunicação. São Carlos: Ed. da UFSCar, 2007.

CHACON, M. C. M. Deficiência mental e integração social: o papel mediador da mãe. Revista Brasileira de Educação Especial, Marília, v.3, n.5, p.87-96, 1999.

MIRA, M.; HOFFAMAN, S. Educational programing for multihandicapped deaf-blind children. Exceptional Children, Reston, v.40, n.7, p.513-514, 1974.

MURDOCH, H. The development of infants who are deaf-blind: a case study. Journal of Visual Impairment \& Blindness, New York, v.88, n.4, p.357-367, 1994.

REGEN, M.; ARDORE, M.; HOFFMANN, V. M. B. Mães e filhos especiais: relato de experiência com grupos de mães de crianças com deficiência. Brasília: CORDE, 1993.

TELFORD, C. W.; SAWREY, J. M. O indivíduo excepcional. 5.ed. Rio de Janeiro: Zahar, 1988.

WATKINS, S. et al. The effectiveness of an intervener model of services for young deaf-blind children. American Annals of Deaf, Washington, v.139, n.4, p.404-409, 1991. 


\section{Como referenciar este artigo}

CADER-NASCIMENTO, Fatima Ali Abdalah Abdel.; COSTA, Maria Piedade Resende da. Intervenção com famílias cujos filhos são surdocegos. Doxa: Rev. Bras. Psicol. Educ., Araraquara, v.19, n.1, p. 20-32, jan./ jun. 2017. ISSN: 1413-2060.

Submetido em: 01/01/2017

Aprovado em: 30/03/2017 